\title{
Path to the Future: Generative Evaluation for Simultaneous Renewal of ICT in Teacher Education and K-12 Schools
}

\author{
Niki Davis, Mari Kemis and Natalie Johnson \\ Center for Technology in Learning and Teaching, Iowa State University, N108 Lagomarcino \\ Hall, Ames, IA 50011-3192,USA,nedavis@iastate.edu
}

\begin{abstract}
Educational organizations, teachers and teacher educators are challenged to renew their practice and to respond to changing community and national demands, including changing technologies. This requires 'simultaneous renewal' of teacher preparation and collaborating K-12 schools. The ongoing development of effective models of ICT-enriched learning and teaching environments in both universities and schools will remain a challenge. There is also the need to develop appropriate methodologies and approaches for researching simultaneous renewal of education across interconnected educational organizations. Two universities and partner elementary schools in the USA have been working on simultaneous renewal of teacher education to develop exemplary practice technology under the initiative to Prepare Tomorrow's Teachers to use Technology (PT3). Iowa State University started first with their project called 'Technology Collaboratives', followed two years later by the University of Florida Technology Initiative project, which draws upon TechCo's approach, strategies and evaluation. The innovative 'generative evaluation' is a key overarching strategy within each project to support their simultaneous renewal and also the inter-project collaboration. This paper proposes that generative evaluation may also inform regional and international collaborations to renew ICT in teacher education thus develop organizations and programs better suited to the teachers and the learners in our future.
\end{abstract}

\section{INTRODUCTION}

Educational organizations, teachers, and teacher educators are challenged to renew their practice and respond to the changing community and national demands, especially from accreditation agencies. This paper takes the case of the notable challenges posed by the integration of (ICT) into teacher

The original version of this chapter was revised: The copyright line was incorrect. This has been corrected. The Erratum to this chapter is available at DOI: 10.1007/978-0-387-35701-0_35 
education and K-12 schools simultaneously. This can be seen as a worldwide phenomenon. In the USA the two major societies for teacher education commissioned working groups to advise the organizations and their memberships on ICT. In Europe, over the last decade, there have been significant national and international efforts to incorporate new technologies in teacher education (Davis, 2001). Additionally, colleagues in Australia reported similar initiatives across their states and more widely in the Pacific region. Most recently, in 2001, the United Nations Education, Scientific and Cultural Organization (UNESCO) appointed a task force to produce guidance for teacher educators integrating ICT in their curriculum, and their guidance document from the task force is starting to be disseminated (UNESCO, in press).

Guidance for the appropriate adoption of ICT to improve education as a whole and teacher education specifically cannot be simple because educational organizations and systems are complex and often chaotic. Education is made up of a number of interacting complex systems, forming an ecology. Change within one group of participants or in the curriculum will be accompanied by complementary changes within and beyond the systems with which it interacts. Leaders will be well advised to appreciate their educational organizations as complex and complicating systems that can only be interpreted though multiple perspectives with a variety of complementary frames (Davis, 2002).

The major complicating factor to the renewal of education is the location of such changes. There is no one location, and so change agents frequently experience a dilemma in choosing where to start. Goodlad (1994) encapsulated this dilemma as follows:

What comes first, good schools or good teacher education programs? The answer is that both must come together. There are not now the thousands of good schools needed for the internships of tens of thousands of future teachers. The long-term solution-unfortunately, there is no quick one-is to renew the two together. There must be a continuous process of educational renewal in which colleges and universities, the traditional producers of teachers, join schools, the recipients of the products, as equal partners in the simultaneous renewal of school and the education of educators. (p. 2)

Goodlad (1994) called for 'simultaneous renewal' of practice in both teacher education and in collaborating K-12 schools where the beginning teachers gain experience and undertake their internships. However, good practice with ICT in teacher education is probably at least as patchy as what takes place in $\mathrm{K}-12$ schools. 
The National Council for Accreditation of Teacher Education (NCATE) Task Force on Technology found that in most teacher education programs, technology is considered an addendum to curriculum and not a cognitive learning tool that is infused throughout the entire teacher education program (National Council for Accreditation of Teacher Education, 1997). Teacher educators reported the following problems when using technology: (1) lack of time to learn about new technologies; (2) lack of technology and technical support; (3) limited number of faculty technology training opportunities; and (4) an academic reward system that does not provide incentives for technology innovation. Several expert groups strongly suggest that colleges and universities must take a leadership role in preparing preservice teachers to use and integrate computer-related technology in schools (Espinoza \& McKinzie, 1994; International Society for Technology in Education, 1998; Office of Technology Assessment, 1995). Since 1999, the USA has been investing in ICT in teacher education through the federal initiative Preparing Tomorrow's Teachers to use Technology (PT3) and significant patches of excellence have developed across the USA.

This paper addresses two of the significant patches of excellence using research and evaluation of simultaneous renewal in two teacher education programs in the USA. These universities faced up to the challenge of simultaneous renewal using ICT as a catalyst to develop good practice and enhance teacher quality in both the universities and strategically chosen $\mathrm{K}$ 12 schools. The K-12 schools chosen welcome student teachers and aim to provide technology-rich field experiences and internships for preservice teachers. Careful attention to in-depth research and development is necessary to find a path to the future. This paper describes the 'generative evaluation' approach that was developed to guide leaders of educational renewal so they, in turn, may guide participants through the chaos of change catalyzed by ICT in university programs, teacher education, and collaborating K-12 partner schools.

\section{THE CONTEXTS}

Two universities in the USA have been working on simultaneous renewal of teacher education with ICT using federal funding under the initiative to Prepare Tomorrow's Teachers to use Technology (PT3, see http://www.pt3.org). Iowa State University (ISU) started first in 2000 with their project called 'Technology Collaboratives' (TechCo). This was followed two years later by the University of Florida Technology Initiative Project (TIP), which draws upon TechCo's approach, strategies, and 
evaluation techniques. The innovative 'generative evaluation' is a key overarching strategy within each project to support their partnerships and also the inter-project collaboration. Both projects are developing their organizational structures, teachers, teacher educators, and leaders in the participating organizations (Thompson, Schmidt \& Davis, 2003).

Both projects work with multiple organizations because teacher education does not take place in one location. Each project's participating organizations include discipline-specific colleges within the universities (Engineering at ISU, and Science at the University of Florida), K-12 partner schools, as well as their teacher education department. ISU also works closely with the local education authority (AEA). Together, all of these organizations collaborate in the development of courses and field experiences that model good practice with infusing new technology for beginning teachers, along with relevant professional and organizational development for the teachers involved. This extensive collaboration is very challenging. In addition, both projects require and welcome collaboration with other PT3 projects, the national PT3 organization, and professional societies.

This paper will not describe the strategies that were developed, shared, and adapted by project leaders. These strategies are described on the web sites and in the academic papers of the projects. As in previous projects, the successful strategies were intensive and eclectic, responding to individual, discipline, and organizational needs that developed over time (Thompson, Schmidt \& Davis, 2003).

\section{GENERATIVE EVALUATION}

The purpose of this paper is to share the successful approach taken to inform and assess simultaneous renewal of education, referred to by us as 'generative evaluation'. It was created to answer the need to develop an appropriate methodology that could be applied to inform a holistic perspective in complex systems. In a separate article the lead author describes the characteristics of complex systems and identifies teacher education as one example (Davis, 2002). It provides examples where an assumption that change is occurring in a simple system has increased the challenge (turbulence) experienced by participants and leaders. We understood that research and evaluation of simultaneous renewal of education across complex and interconnected educational systems is complex and messy. We used our understanding of educational change models (see Ellsworth, 2000, and Sherry, 2002, for surveys of change models) to provide a well-researched structure through which to interpret the 
repeating patterns and pathways through the chaos evidenced in complex systems striving for renewal.

The approach draws upon Davis' (2001) discussion of the active involvement of participants in the process and related developments in evaluation. Experts on program evaluation (House, 1993; Schorr, 1997; Shadish, Cook \& Leviton, 1991) all indicate that program evaluation has undergone a major transformation in the last three decades. There is now recognition of the influence of multiple interests at work. Evaluation has changed from single external views of objective judgments to pluralist conceptions, with multiple perspectives, audiences, measures, methods, and criteria. Implementation analysis becomes particularly important under these conditions. Evaluation must take into account all the different organizations, constituencies, and individuals in different phases of technology integration, including:

- Acquisition and installation of hardware and software;

- Training of teacher educators, teachers, their leaders, support staff, and communities;

- Integrating technology into the curriculum and instruction, especially into discipline specific (content) methods courses;

- Evolution of the institutions and the academic programs within and beyond their traditional boundaries; and the

- Transferring of good practice across institutions and educational systems.

The education of the project leaders was recognized as an important part of the 'generative evaluation' process. An approach that educates participants to become more effective professionally as well as to become members of the evaluation or research teams has been successfully implemented in previous ICT projects. For example, Bridget Somekh, as leader of the Pupil Autonomy and Learning with Microcomputers (PALM) project, explicitly set out to support teachers to change practice in their classroom by educating them to adopt action research as well as skills and knowledge with ICT (see Somekh \& Davis, 1997, and Somekh in the Educational Research Forum http://telematics3.ex.ac.uk/erf). In a simpler approach, Davis et al (1997) used examples of ICT in teacher education to survey the needs of teacher educators across Europe with an additional objective of raising their awareness of the potential range of ICT applications.

Generative evaluation educates each project leader at several levels as it gathers both formative and summative data on the structures, undergoing renewal, and related activities. The process is informed by theories of change in education. The process often results in leaders generating and adapting 
strategies and actions to expedite change and educational renewal, hence, the name chosen. This is illustrated in the next section.

\subsection{The interview process}

The generative evaluation technique takes the form of a structured interview of a project leader conducted by two researchers well versed in educational change. This intensive interview took place in a room with a whiteboard upon which one interviewer developed a very messy version of figure 1, annotated with labels and descriptions provided by the interviewee. The second interviewer provides additional depth to the explanation of the change models in use and managed the time spent on each section.

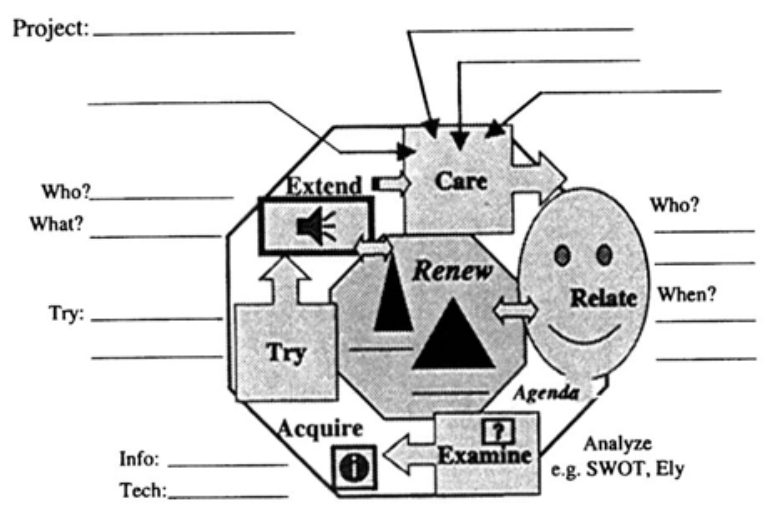

Figure 1. Planning change with CREATER+ (after Havlock \& Zlotolow, in Ellsworth, 2000)

First, the interviewer captured the leader's personal view of the organizations involved in educational renewal and their relationships. An adaptation of Steve Bosserman's model of institutional change was used to interpret the leader's perception of the educational systems undergoing educational renewal under her shared leadership. Bosserman encourages us to think in terms of formal structures (denoted by triangles), but also in terms of the larger environment in which we function (Bosserman cited in Silag \& Fields, 2001, p. 68).

Once the arena for simultaneous renewal was established, the six steps for a change agent postulated in Havelock and Zlotolow's (1995) CREATER model (Ellsworth, 2000) were then explored and points added to the white board one by one, starting with Care. The six steps in the CREATER model replaced Bosserman's five stages, and were similar. Where relevant, other models of educational change were introduced. For example, Hall, George 
and Rutherford (1985) focus on the Concerns of the individual in their Concerns Based Adoption Model (CBAM) and in our generative model Concerns accompanies Care because there were commonalities between these stages. Ely's (Ellsworth, 2000) environmental conditions of change and tenets of Rogers' (Ellsworth, 2000) 'observability' stage in his diffusion of innovation model were often used at the Examine stage of our model. Each element of the model was explained to the interviewee. Following the explanation, the interviewee was requested and encouraged to provide examples or give suggestions based on personal experience with an individual project.

The interviewer sketched the examples and suggestions into the developing image on the whiteboard. This process allowed for verification and occasional corrections when necessary. Each interview ended with an invitation for interviewees to reflect on and respond to the value of this type of interview. The interviews were conducted twice, and each was scheduled for an hour. During the first round of interviews more time was spent on the early stages of the model. However, the second interviews were timed so that adequate time was spent for the important final stage Extend. This is the stage where the lessons learned are uncovered with reflection on the educational renewal that had taken place. Having ninety minutes for the interviews would allow us to better explore the issues, had it been available.

\subsection{Data analysis}

The analysis of data started at the time of the interview with the construction of a current personal perspective of the system undergoing educational renewal and the stages of action in the CREATER cycle. This was constructed and verified between the leader interviewed and the two researchers as interviewers. As noted above, modifications to the content on the whiteboard were made when necessary during the interviews. This data on the white board were photographed, 'transcribed' and presented into a graphic form. The details of the interview were also transcribed, verified with participants and analyzed against the diagram to provide a full, rich, and holistic picture. Both pairs of leaders were interviewed for both projects during their first year. The two leaders of the TechCo project were also interviewed in the third year of their project (2002). In addition, the generative evaluation technique was modified and developed into a worksheet for use in three conference workshops to assist leaders and change agents think strategically about planned change. 


\section{FINDINGS}

On every occasion the interviewees indicated that the interview experience was valuable and energizing, with the exception of the interview we conducted with both the Dean and assistant Dean together. These leaders were not project managers leaders and we also feel that the joint interview resulted in confusion between two individuals' perceptions.

On all other occasions the intensive interview generated strategies that the participants felt led to improvement of their project management and leadership. The first intensive interview for Ann Thompson in year 1 of the project showed that she was intuitively strong on the Relate process early in the project, with few activities planned to move into the Try phase and into lessons learned for Extend. This was a common finding in all the interviews early in the project. Ann recognized this and adjusted the agenda for project meetings, conference presentations and papers for dissemination that encouraged partners across the consortium to share their 'Trys' plus the lessons that they learned.

Denise Schmidt generated additional faculty participation in partnering $\mathrm{K}-12$ schools focusing on 'Trys' to encourage the extension, transfer and reciprocating of those lessons learned into university courses in the teacher education program. The leaders of the UFTIP project also generated additional collaborative activities between more schools and their teacher education program. Participants in the four workshops generated new plans as well as an overarching view of their project, and on all occasions at least one participant remarked on how the process helped in the reconceptualization of planned change and their role in the process.

To date, only two rounds of interviews with project leaders have been conducted that permit us to examine the data for evidence of simultaneous renewal. In each case, comparison of the central circle of renewal for interviews one and two shows a significant change in the renewal taking place in each university and partnering $\mathrm{K}-12$ schools as these organizations move simultaneously.

The use of a schematic diagram to depict organizational structures shows the close collaboration and partnership that have developed during the project (developed from Bosserman in Silag \& Fields, 2001). During educational renewal the process is not static and changes within collaborating organizations move closer or overlap their boundaries indicating that simultaneous renewal is underway and likely to succeed in the longer term.

Denise Schmidt, TechCo's second leader, produced a similar perspective in year 3 of the project. During her second interview she explained relationship building as one of the major lessons learned (Extend): 
...building relationships and trust is one of the things that I learned....to do things right, you need an audience is manageable....just being able to organize or even able to provide leadership for a project....they know you won't lead them down the wrong path and I think that's important. So building those are huge. (DS interview October, 2002)

The building of these relationships with the four K-12 schools and their local educational agency (AEA) led to many collaborative activities and support. As a result, these partners were pulled together more closely. This view stands out at the forefront of Denise and Ann's perspective of renewal taking place in teacher education with ICT.

In summary our novel 'generative evaluation' technique has developed successfully over two years to address six objectives:

- To inform both projects' management as the projects evolved

- To educate the project leaders about appropriate and timely models of educational change

- To encourage and support action research by project participants

- To inform leadership of simultaneous renewal in education across multiple organizations

- To provide formative evaluation assessment of simultaneous renewal that took place in both projects that took place, if any

- To research and further develop the technique of 'generative evaluation'.

\section{CONCLUSION}

A path to a future in which well-prepared teachers can effectively deploy ICT in K-12 schools and good practice is modeled in teacher education can be hard to find. We know that good practice and effective integration of ICT must include simultaneous renewal across many organizations. Our collaboration across organizations involved in two PT3 projects and across PT3 projects has been successful in further embedding ICT into systems and organizations in one university and establishing that process in the second. We learned that pockets of excellence in teacher quality could be developed. However, we also recognize that simultaneous renewal is complex and fragile, requiring sustained and well-informed leadership (Sherry, 2002). The development of 'generative evaluation' for simultaneous renewal of ICT in teacher education holds promise for the transfer of a robust approach that is transferable and applicable to other projects and partnerships.

This paper provides early evidence that 'generative evaluation' can guide leaders and change agents on their pathway to the future. We believe that the 
intensive support of leaders who heroically struggle for simultaneous renewal of education is important. There are also indications that leaders will benefit from this approach and technique even when ICT is not involved as a catalyst for change. It is proposed that this innovative approach to formative and summative evaluation of change in the complex systems that make up teacher education will be valuable to other cultures and contexts. Generative evaluation as an approach may also inform regional and international collaborations to renew ICT in teacher education, further developing organizations and programs that are better suited to meet the needs of change agents, teachers, and the learners of the future.

\section{ACKNOWLEDGEMENTS}

The participation and support of colleagues at Iowa State University and the University of Florida are acknowledged. Specifically, thanks to Ann Thompson, Denise Schmidt, Kara Dawson, Colleen Swain, and ISU's TechCo coordinator Clyciane Michalini. The contents of this paper were developed in association with two grants from the Fund for Improvement of Post Secondary Education (FIPSE), and the US Department of Education. However, the contents do not necessarily represent the policy of the Department of Education, and you should not assume endorsement by the Government.

\section{REFERENCES}

Davis, N. E. (1997). Telematics applied to the training of teachers: A survey via video conferencing across Europe. European Journal of Teacher Education, 20(1), 49-60.

Davis, N. E. (2001). International contrasts of information technology in teacher education: Multiple perspectives on change (Editorial). Journal of Information Technology for Teacher Education, 9, 139-147.

Davis, N. E. (2002). Leadership of information technology for teacher education: A discussion of complex systems with dynamic models to inform shared leadership. Pedagogy, Education and Technology, 11(3), 253-272.

Davis, N. E, Hawkes, M., Heineke, W. \& Veen, W. (2001). Multiple perspectives on evaluation of new technology in education and teacher education. In W. Heineke, L. Blaise \& J. Willis (Eds), Research Methods in Educational Technology (Vol. 1: Methods of evaluating educational technology). Greenwich, CT: Information Age Publishing.

Ellsworth, J. (2000). Surviving Change: A Survey of Educational Change Models. Syracuse, NY: ERIC Clearing House on Information and Technology.

Espinoza, S. \& McKinzie, L. (1994). Internet activities open new worlds for educators. Technology and Teacher Education Annual, 666-670.

Goodlad, J. (1994). Educational Renewal. San Francisco: Jossey-Bass Publishers.

Hall, G., George, A. \& Rutherford, W. (1979). Measuring Stages of Concern about the Innovation: A Manual for Use of the SoC Questionnaire. The University of Texas at Austin.

House, E. (1993). Professional Evaluation. Newbury Park, Beverley Hills, CA: Sage. 
International Society for Technology in Education (1998). Survey: Information Technology in Teacher Education. Retrieved from http://www.iste.org

Lane, C. \& Cassidy, S. (1994). The role of technology in the systemic reform of education and training. ED Journal, 8, 1-22.

Milken Exchange on Education Technology (1999). Will New Teachers be Prepared to Teach in a Digital Age? Santa Monica, CA: Milken Family Foundation.

National Council for Accreditation of Teacher Education (1997). Technology and the New Professional Teacher: Preparing for the $21^{\text {st }}$ Century Classroom. Washington D.C.: Author.

Office of Technology Assessment (1995). Teachers and Technology: Making the Connection. (Report no. OTA-EHR-616). Washington, DC: U.S. Government Printing Office.

Panel on Educational Technology (1997). Report to the President on the Use of Technology to Strengthen K-12 Education in the United States. Washington, DC.

Schorr, L. B. (1997). Common Purpose: Strengthening Families and Neighborhoods to Rebuild America. New York: Anchor Books Double Day.

Schrum, L. (1994). First steps into the information age: Technology infusion in a teacher education program. Journal of Computing in Teacher Education, 10, 12-14.

Shadish, W. R., Cook, T. D. \& Leviton, L. C. (1991). Foundations of Program Evaluation: Theories of Practice. Newbury Park: Sage Publications.

Sherry, L. (2002). Sustainability of innovations. Journal of Interactive Learning Research, 13, 211-238.

Silag B. \& Fields A. (2001). Creating the Engaged University. Iowa's Model for Change. Ames, Iowa: Iowa State University Extension.

Somekh B. and Davis N. E. (Eds.) (1997). Using IT Effectively in Teaching and Learning: Studies in Pre-service and In-service Teacher Education. Routledge: London and New York.

Thompson, A., Schmidt, D. \& Davis, N. E. (2003). Technology collaboratives for simultaneous renewal in teacher education. Educational Technology Research and Development, 5l(1), 71-87.

UNESCO (in press). ICT Teacher Education. Guidance. Paris: UNESCO. 